\title{
Implications of Lagrangian transport for simulations with a coupled chemistry-climate model
}

\author{
A. Stenke, M. Dameris, V. Grewe, and H. Garny \\ Deutsches Zentrum für Luft- und Raumfahrt (DLR), Institut für Physik der Atmosphäre, Oberpfaffenhofen, Germany
}

Received: 4 July 2008 - Published in Atmos. Chem. Phys. Discuss.: 31 October 2008

Revised: 18 May 2009 - Accepted: 29 July 2009 - Published: 4 August 2009

\begin{abstract}
For the first time a purely Lagrangian transport algorithm is applied in a fully coupled chemistry-climate model $(\mathrm{CCM})$. We use the numerically non-diffusive Lagrangian scheme ATTILA instead of the operational semiLagrangian scheme for the transport of water vapour, cloud water and chemical trace species in the CCM E39C. The new model version including the Lagrangian scheme is referred to as E39C-A. The implications of the Lagrangian transport scheme for stratospheric model dynamics and tracer distributions in E39C-A are evaluated by comparison with observations and results of the previous model version E39C. We found in a previous paper that several deficiencies in stratospheric dynamics in E39C originate from a pronounced modelled wet bias and an associated cold bias in the extra-tropical lowermost stratosphere. Contrary to the semi-Lagrangian scheme ATTILA shows a largely reduced meridional transport of water vapour from the tropical upper troposphere into the extratropical lowermost stratosphere. The reduction of the moisture and temperature bias in E39C-A leads to a significant advancement of stratospheric dynamics in terms of the mean state as well as annual and interannual variability. In this study we show that as a consequence of both, the favourable numerical characteristics of the Lagrangian transport scheme and the improved model dynamics, E39C-A generally shows more realistic distributions of chemical trace species: Compared to E39C high stratospheric chlorine $\left(\mathrm{Cl}_{\mathrm{y}}\right)$ concentrations extend further downward. Therefore E39C-A realistically covers the altitude of maximum ozone depletion in the stratosphere. The location of the ozonopause, i.e. the transition from low tropospheric to high stratospheric ozone values, is also clearly improved in E39C-A. Not only the spatial distribution but also the temporal evolution of strato-
\end{abstract}

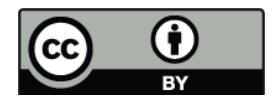

Correspondence to: A. Stenke (andrea.stenke@dlr.de) spheric $\mathrm{Cl}_{\mathrm{y}}$ in the past is realistically reproduced in E39C-A which is an important step towards a more reliable projection of future changes, especially of stratospheric ozone. Despite a large number of improvements there are still remaining model deficiencies like a general overestimation of total column ozone.

\section{Introduction}

Coupled chemistry-climate models (CCMs) are a common tool to study past changes and to predict the future evolution of the stratosphere. Assessing the reliability of those model predictions requires a detailed knowledge of the capabilities and limitations of the applied models. For this purpose different generations of CCMs and their underlying general circulation models (GCMs) are reviewed periodically in various model intercomparison projects (e.g. Park et al., 1999; Gates et al., 1999; Pawson et al., 2000; Austin et al., 2003). In a recent model intercomparison (Eyring et al., 2006) the performance of thirteen CCMs has been evaluated against observations with a special focus on quantities that are important for simulating the evolution of ozone and ozone recovery. The participating models covered a great bandwidth of different model formulations, e.g. with respect to the underlying GCMs, transport algorithms, chemistry schemes or the model domain and resolution. Depending on the evaluated quantity the models showed more or less agreement among each other or with observations. For example, most models showed a temperature bias in the extra-tropical lowermost stratosphere, but the simulated stratospheric temperature trend over the period between 1960 and 2000 was in fairly good agreement with observations. A large intermodel spread, however, was obvious in the simulated tracer distributions like those of methane or inorganic chlorine $\left(\mathrm{Cl}_{\mathrm{y}}\right)$, indicating large differences in transport. This kind of

Published by Copernicus Publications on behalf of the European Geosciences Union. 
model evaluation can provide useful insights in model deficiencies and general uncertainties in our understanding of mechanisms and feedback processes. For the identification of causes of model shortcomings a more detailed analysis of model results and sensitivity simulations with respect to individual parameterisations are necessary.

One of the participating models was the CCM ECHAM4.L39(DLR)/CHEM (hereafter referred to as E39C, Dameris et al., 2005), consisting of the general circulation model ECHAM4.L39(DLR) and the chemistry module CHEM. The model evaluation of Eyring et al. (2006) summarised various shortcomings in E39C with respect to model dynamics and tracer distributions. Like most of the models, E39C exhibits a severe temperature bias in the extratropical lowermost stratosphere (cold bias) as well as in polar regions in the model top layers (see also Dameris et al., 2005). The stratospheric temperature errors have further implications for model dynamics like a delayed break down of the polar vortex (Hein et al., 2001). Furthermore, the comparison with observations indicated biases in simulated tracer fields which might be caused by deficiencies in model dynamics as well as limitations of the applied transport algorithm. For example, the atmospheric tape recorder signal in E39C indicates a too rapid upward propagation in the tropics. E39C also has problems simulating the stratospheric methane distribution or stratospheric $\mathrm{Cl}_{\mathrm{y}}$ trends. The latter has an impact on simulated ozone trends which are too weak in E39C. The exact cause and effect relationships causing these model deficiencies are generally not obvious and figuring them out is often challenging. Compared to the other participating models E39C has the lowest vertical resolution above $50 \mathrm{hPa}$, with the uppermost model level being centred at $10 \mathrm{hPa}$. Thus E39C deficiencies are often simply attributed to the low model top.

A first important step towards a significant improvement of model dynamics has been done in a recent study of Stenke et al. (2008) employing the fully Lagrangian, numerically non-diffusive, and strictly mass conserving advection scheme ATTILA (Reithmeier and Sausen, 2002) for the transport of water vapour and cloud water in the ECHAM4.L39(DLR) GCM (without coupled chemistry). In the operational version (e.g. Roeckner et al., 1996; Land et al., 2002) a semi-Lagrangian advection scheme is used for tracer transport which exhibits an exceptional high numerical diffusion in the presence of sharp tracer gradients. In case of water vapour this leads to an artificial horizontal diffusion of water vapour from the tropical upper troposphere into the extra-tropical lowermost stratosphere and a severe overestimation of water vapour (wet bias) by a factor of 3-5 compared to HALOE observations. In turn, the wet bias contributes to a cold bias in the extra-tropical lowermost stratosphere due to excessive longwave cooling rates. The use of ATTILA results in a pronounced and consistent reduction of the modelled biases, e.g. the cold bias in the extra-tropical lowermost stratosphere is reduced to one third of its original amount. The advancements in simulated temperatures have a remarkable impact on model dynamics, e.g. on the representation of the extra-tropical tropopause or the zonal winds in the stratosphere.

In the present study the Lagrangian approach described in Stenke et al. (2008) has been extended to a model version including an interactively coupled chemistry module, i.e. in addition to water vapour and cloud water all chemical trace species are transported by ATTILA. Furthermore, this time also the feedback effects of the radiatively active gases ozone, methane, nitrous oxide and chlorofluorocarbons are included. According to our knowledge this is the first time that a purely Lagrangian advection scheme is used for the transport of active trace species in a global, interactively coupled CCM. Lagrangian methods have been applied in chemistry transport models (CTMs) like STOCHEM (Collins et al., 2000, and references therein), GRANTOUR (e.g. Atherton et al., 1996) or CLaMS (McKenna et al., 2002a,b; Konopka et al., 2004) exclusively, with encouraging results. Furthermore, in a few cases Lagrangian schemes have been used in GCMs for the transport of passive trace species (e.g. Eluszkiewicz et al., 2000; Reithmeier and Sausen, 2002). Here we present E39C-A, an upgraded model version of the coupled chemistry-climate model E39C, employing the Lagrangian advection scheme ATTILA for transport of water vapour, cloud water, and chemical tracers. The intention of this paper is to evaluate the performance of this new model version, particularly with regard to model stratospheric dynamics and simulated tracer distributions, documenting significant improvements but also identifying remaining model deficiencies that cannot be cured by a superior transport algorithm. Though the model includes the above mentioned coupling between chemistry and climate, there is no detailed investigation of how this coupling is affected by the change of the advection scheme, except insofar as the distributions of these trace gases change. Like the evaluation of Eyring et al. (2006), this study is based on a transient model simulation of the year 1960 to 2004 including several anthropogenic and natural forcings.

In the following section E39C-A as well as the experimental set-up of the model simulation are briefly described. Several advancements in model dynamics have already been discussed in Stenke et al. (2008) and are briefly summarised in Sect. 3.1. Sections 3.2 and 3.3 focus on model improvements with regard to stratospheric transport and tracer distributions. A summary and concluding remarks are given in Sect. 4.

\section{Model description and experimental set-up}

\subsection{The CCM ECHAM4.L39(DLR)/CHEM/ATTILA}

In this study, we present the coupled chemistry-climate model ECHAM4.L39(DLR)/CHEM/ATTILA (hereafter referred to E39C-A) which is an upgraded version of the 
CCM ECHAM4.L39(DLR)/CHEM (E39C, Dameris et al., 2005). The new model version E39C-A is identical to the reference version $\mathrm{E} 39 \mathrm{C}$, except that we employ the fully Lagrangian advection scheme ATTILA (Reithmeier and Sausen, 2002) instead of the operational semi-Lagrangian scheme (Williamson and Rasch, 1994) for tracer transport. An overview of the different model versions used in this study is given in Table 1 .

The reference model E39C consists of the dynamic part ECHAM4.L39(DLR) and the chemistry module CHEM. ECHAM4.L39(DLR) (Land et al., 2002) is a derivate of the climate model ECHAM4 (Roeckner et al., 1996), with an enhanced vertical resolution from 19 to 39 levels. The model top layer is centred at $10 \mathrm{hPa}$. In the uppermost model layers ("sponge layer") horizontal diffusion is gradually enhanced to prevent spurious wave reflection at the model top. These numerical requirements yield a suppressed model variability in the 2 uppermost layers, i.e. above $25 \mathrm{hPa}$. A spectral horizontal resolution of $\mathrm{T} 30\left(\approx 6^{\circ}\right.$ isotropic resolution) is used in this study. The corresponding Gaussian transform grid, on which the tracer transport, model physics and chemistry are calculated, has a mesh size of approximately $3.75^{\circ} \times 3.75^{\circ}$. The chosen time step is $24 \mathrm{~min}$.

The chemistry module CHEM (Steil et al., 1998) is based on the family concept. It includes stratospheric homogeneous and heterogeneous ozone chemistry and the most relevant chemical processes for describing the tropospheric background chemistry with 107 photochemical reactions, 37 chemical species and 4 heterogeneous reactions on polar stratospheric clouds (PSCs) and on sulphate aerosols. In addition to $\mathrm{E} 39 \mathrm{C}$ the present model version $\mathrm{E} 39 \mathrm{C}-\mathrm{A}$ includes a parameterisation for bromine chemistry $(\mathrm{ClO} / \mathrm{BrO}-$ cycle) based on the photolysis of $\mathrm{Cl}_{2} \mathrm{O}_{2}$ (based on Rex et al., 2003, a detailed description of the parameterisation is given in the supplement, see http://www.atmos-chem-phys.net/9/ 5489/2009/acp-9-5489-2009-supplement.pdf). To account for the effects of twilight stratospheric ozone chemistry the photolysis at solar zenith angles up to $93^{\circ}$ has been implemented (Lamago et al., 2003). Net heating rates and photolysis rates are calculated on-line from the modelled distributions of the radiatively active gases $\mathrm{O}_{3}, \mathrm{CH}_{4}, \mathrm{~N}_{2} \mathrm{O}, \mathrm{H}_{2} \mathrm{O}$ and $\mathrm{CFCs}$, and the actual cloud distribution. $\mathrm{NO}_{\mathrm{x}}$ emissions from lightning are parameterised according to the approach developed by Grewe et al. (2001) who related the flash rate to the vertical mass flux within a convective cloud. The annual mean emission rate of lightning $\mathrm{NO}_{\mathrm{x}}$ amounts to $5.36 \mathrm{Tg}(\mathrm{N}) / \mathrm{yr}$.

In the upgraded model version E39C-A water vapour, cloud water and chemical trace species are advected by the Lagrangian advection scheme ATTILA (Reithmeier and Sausen, 2002) instead of the operational semi-Lagrangian advection scheme of Williamson and Rasch (1994) which was used in the reference model version E39C. Since the semi-Lagrangian scheme itself is not mass conserving, a mass fixer has to be applied which is an integral part of the scheme (Rasch and Williamson, 1990). In contrast, the purely Lagrangian scheme ATTILA is strictly mass conserving and numerically non-diffusive. Transport studies with the ECHAM4 GCM using passive tracers have shown that ATTILA is able to maintain steeper and more realistic gradients than the semi-Lagrangian scheme (Reithmeier and Sausen, 2002). Furthermore, the simulated age of air in ECHAM4 strongly depends on the advection scheme, with ATTILA producing the older and more realistic ages (Land et al., 2002; Reithmeier et al., 2008). This agrees well with findings of Eluszkiewicz et al. (2000) that the most realistic results in terms of age of air are obtained with non-diffusive schemes. However, even with ATTILA the mean age of air outside of the tropics is still underestimated in ECHAM4.

To cope with the applied spatial resolution (T30, 39 vertical levels) the mass of the model atmosphere is divided into approximately 500000 air parcels of equal mass which are advected three-dimensionally using the actual model wind field. ATTILA includes state-of-the-art parameterisations of convective transport, mixing due to inter-parcel exchange, and boundary layer turbulence which are described comprehensively by Reithmeier and Sausen (2002).

Reithmeier and Sausen (2002) applied ATTILA for the transport of passive tracers exclusively. In a recent study by Stenke et al. (2008), ATTILA has been extended successfully to water vapour and cloud water. The treatment of active trace species requires some modifications to ATTILA concerning the mapping between air parcels and model grid. The model grid is used for the calculation of radiation, convection and other physical processes, and to handle the diagnostic output. For this purpose, the tracer concentrations are mapped from the air parcels to the ECHAM model grid by averaging the tracer concentrations of all air parcels within the same grid box. Since the radiation scheme requires complete tracer fields, a suitable algorithm is used to "fill" empty grid boxes, i.e. a reasonable tracer concentration is assigned to the respective grid box. A detailed description of the applied approach is given in Stenke et al. (2008).

In the present study the concept described in Stenke et al. (2008) has been adopted for the transport of chemical trace species. While in case of water vapour and cloud water the tracer content on the Lagrangian air parcels is given as mass mixing ratios, volume mixing ratios are used in case of the chemical trace species.

\subsection{Experimental set-up}

The present study is based on a transient simulation designed to represent the atmospheric development from 1960 to 2004. Therefore, as many as possible natural and anthropogenic forcings are included, like the 11-year solar cycle, the QBO, chemical and direct radiative effects of major volcanic eruptions, the increase in well mixed greenhouse gas concentrations and surface $\mathrm{NO}_{\mathrm{x}}$ emissions. The model design mainly follows the description given in Dameris et al. (2005). In 
Table 1. Model versions used in this study.

\begin{tabular}{llccc}
\hline Model & Long Name & Coupled Chemistry & Advection Scheme & Resolution/Domain \\
\hline E39 & ECHAM4.L39(DLR) & no & Semi-Lagrangian & T30, 39 Levels, $10 \mathrm{hPa}$ \\
E39-A & ECHAM4.L39(DLR)-ATTILA & no & Lagrangian (ATTILA) & T30, 39 Levels, 10 hPa \\
E39C & ECHAM4.L39(DLR)/CHEM & yes & Semi-Lagrangian & T30, 39 Levels, 10 hPa \\
E39C-A & ECHAM4.L39(DLR)/CHEM-ATTILA & yes & Lagrangian (ATTILA) & T30, 39 Levels, 10hPa \\
\hline
\end{tabular}

the following, the experimental set-up and modifications compared to Dameris et al. (2005) are briefly summarised. After a 10-year spin-up with stationary conditions of the late 1950s the model has been integrated from 1960 to 2004 using transient boundary conditions.

The SSTs are given as monthly means following the global sea ice and sea surface temperature data set HadISST1 provided by the UK Met Office Hadley Center (Rayner et al., 2003, available via http://hadobs.org/). The data set is based on merged satellite and in situ observations.

Both, chemical and direct radiative effects of enhanced stratospheric aerosol abundance from the three major volcanic eruptions of Agung (1963), El Chichón (1982) and Mount Pinatubo (1991) are taken into account. For the heterogeneous reactions covered in the chemistry module, observed sulphate aerosol surface area densities (SADs) are prescribed as monthly means. The SADs have been deduced from satellite data, as described in Jackman et al. (1996) and updated by D. B. Considine (NASA Langley Research Center). This data set covers the period from 1979 to 1999. For the years before 1979 SADs have been calculated as described in Dameris et al. (2005), and for the period 20002004 the mean value of the years 1997 to 1999 has been used.

Additional radiative heating by volcanic aerosols is implemented using additional monthly and zonal mean net heating rates. The heating rates mark a modification to the model set up described in Dameris et al. (2005) who used a data set provided by Kirchner et al. (1999). The heating rates applied in the present study were calculated by G. Stenchikov and L. Oman using volcanic aerosol parameters from Sato et al. (1993), Hansen et al. (2002) and GISS Model E radiative routines and climatology (Schmidt et al., 2006, for further information see http://www.pa.op.dlr.de/CCMVal/Forcings/ CCMVal_Forcings.html). This data set covers the years from 1950 to 1999 . For the years 2000 to 2004 the values of 1999 have been used. In tropical regions the updated volcanic heating rates are generally smaller than in the data set of Kirchner et al. (1999). In polar regions of the lower stratosphere the new data set shows a substantial radiative cooling for 2-3 years after a volcanic eruption which was not apparent in the data set of Kirchner et al. (1999).

The QBO is forced externally by a linear relaxation ("nudging") of the simulated zonal winds in the equatorial stratosphere to a constructed QBO time series which fol- lows observed equatorial zonal wind profiles (Giorgetta and Bengtsson, 1999). This assimilation is applied equatorwards of $20^{\circ}$ latitude from $90 \mathrm{hPa}$ up to the model top layer. The relaxation time scale is set uniformly to 7 days within the QBO core domain above $50 \mathrm{hPa}$ and between $10^{\circ} \mathrm{N}$ and $10^{\circ} \mathrm{S}$. Outside the core region the relaxation time depends on latitude and pressure (Giorgetta and Bengtsson, 1999).

The influence of the 11-year solar cycle on photolysis is parameterised according to the intensity of the $10.7 \mathrm{~cm}$ radiation of the sun (Lean et al., 1997, data available via http://www.drao.nrc.ca/icarus/www/daily.html). The impact of solar activity on short-wave radiative heating rates is considered on the basis of changes of the solar constant (Dameris et al., 2005, their Table 2).

The temporal development of the mixing ratios of the most relevant greenhouse gases $\left(\mathrm{CO}_{2}, \mathrm{~N}_{2} \mathrm{O}, \mathrm{CH}_{4}\right)$ is based on IPCC (2001). CO $\mathrm{CO}_{2}$ is prescribed as atmospheric mean volume mixing ratio, the others at the surface according to Hein et al. (1997). Nitrogen oxide $\left(\mathrm{NO}_{\mathrm{x}}=\mathrm{NO}+\mathrm{NO}_{2}\right)$ emissions from several natural (lightning, biomass burning, soils) and anthropogenic (industry, aircraft, ships, surface transportation) sources are considered in the model simulation. $\mathrm{NO}_{\mathrm{x}}$ emissions from lightning (Sect. 2.1), soils, ships and aircraft follows the description in Dameris et al. (2005). $\mathrm{NO}_{\mathrm{x}}$ emissions from industry, biomass burning and surface transportation are based on the RETRO emission inventory which means another modification to the model set up in Dameris et al. (2005). A detailed description of the RETRO data set can be found in van het Bolscher et al. (2007, report available via http://retro.enes.org/pub_reports.shtml).

To account for exchange processes from the upper stratosphere, boundary conditions for the two families $\mathrm{ClX}\left(=\mathrm{HCl}+\mathrm{ClONO}_{2}+\mathrm{ClOx}\right)$ and $\mathrm{NO}_{\mathrm{y}}\left(=\mathrm{NO}_{\mathrm{x}}+\mathrm{HNO}_{3}\right)$ are prescribed at the uppermost model level $(10 \mathrm{hPa})$. Monthly mean concentrations are taken from the twodimensional middle atmosphere model by Brühl and Crutzen (1993) (a short description of the model can be found in Sheel et al., 2005). Furthermore, chlorofluorocarbons (CFCs) are not explicitly transported in E39C. Instead twodimensional distributions (depending on latitude and altitude) of CFCs based on the results from the 2-D model by Brühl and Crutzen (1993) are prescribed. Using this kind of boundary conditions the CCM results are certainly influenced by the information provided by the 2-D model. 
For example, the temporal development of the mean total inorganic chlorine $\left(\mathrm{Cl}_{\mathrm{y}}\right)$ mixing ratio prescribed at the model top is shown in Fig. 8 (grey line). The temporal development of CFC concentrations is in agreement with the assumptions made in WMO (2003).

\section{Results}

The advanced numerical properties of the Lagrangian advection scheme used in the new model version E39C-A lead to tracer distributions different from those in the reference model E39C. In a fully coupled CCM these changes modify radiative heating rates and, eventually, model dynamics. The study of Stenke et al. (2008) has shown how the improvements with respect to the simulated water vapour distribution arising from the use of ATTILA directly feed back to modelled temperatures and other dynamic variables. In turn changes in model dynamics feed back to the transport characteristics of a model.

In the following we will assess the impact of the Lagrangian advection scheme ATTILA on chemical tracer distributions and model dynamics in the CCM E39C-A, with a special focus on the stratosphere. Another important question is how changes in the mean model climate and mean tracer distributions affect simulated long-term changes and variability. This aspect is of particular interest in view of the need for reliable estimates of future changes.

\subsection{Stratospheric dynamics}

In a previous paper Stenke et al. (2008) have reported obvious improvements regarding model dynamics in response to the use of the Lagrangian advection scheme ATTILA for the transport of water vapour and cloud water in the GCM ECHAM4.L39(DLR). The model version of ECHAM4.L39(DLR) using the Lagrangian advection scheme is hereafter referred to as E39-A (see Table 1). The key result is a significant reduction of a severe wet bias in the extra-tropical lowermost stratosphere which contributed to a strong cold bias within this atmospheric region due to excessive longwave cooling rates. In response to the reduced wet and cold bias further aspects of model dynamics are clearly improved. All the improvements with regard to the simulated water vapour distribution and stratospheric dynamics apparent in time slice simulations with E39-A are also found in the transient simulation with E39C-A including interactively coupled chemistry. In the following the main results of Stenke et al. (2008) are briefly summarised to provide a basis for the subsequent discussions: the simulated tropopause characteristics in E39-A are in better agreement with respective ERA40 data, in particular in extra-tropical regions where the simulated tropopause is clearly shifted downward (cp. Fig. 10 in Stenke et al., 2008). The climatological mean zonal wind fields for solstice conditions are improved with regard to ERA40 re-analyses (Uppala et al., 2005). The strength of the polar night jets is slightly reduced (e.g. by about $5 \mathrm{~m} / \mathrm{s}$ in the Southern Hemisphere), but still stronger than observed. The most obvious upgrade is found during summer months with both hemispheres showing a much better representation of the downward propagation of the zero wind line into the lower stratosphere, i.e. the transition from westerlies to easterlies between November and January in the Southern Hemisphere and between June and August in the Northern Hemisphere (cp. Fig. 11 in Stenke et al., 2008). Both, the CCM E39C and the underlying GCM E39 are not able to simulate adequately the observed wind reversal in the stratosphere below $10 \mathrm{hPa}$ in a realistic manner, especially in the Southern Hemisphere (Dameris et al., 2005). The upgrades of E39-A are also visible in the mean annual cycle of both the zonal mean wind and temperature in the lower stratosphere (cp. Fig. 12 in Stenke et al., 2008). Moreover, it is worth mentioning that the interannual dynamical variability is enhanced during Northern Hemisphere winter season, particularly in early winter months which is in better agreement with observations.

In the following we will concentrate on consequent advancements in interactions between planetary waves and the mean flow in terms of Eliassen-Palm (EP) fluxes and the meridional heat flux. Wave propagation and dissipation are key drivers of stratospheric transport and variability, and it is important to reasonably simulate the impact of changes in wave activity on stratospheric dynamics and therefore on the future evolution of stratospheric ozone (a key objective when using CCMs).

Both, EP fluxes and EP divergence fields during solstice conditions as simulated with the reference model version E39C and the upgraded model version E39C-A are presented in Fig. 1 for the lower stratosphere. The EP fluxes were calculated including ageostrophic terms as given in Robinson (1986, their Eq. 5) and were weighted by the mass of an annular ring $d \varphi d p^{1}$ (Edmon et al., 1980). The transfer of wave energy from one latitude and height to another, i.e. the direction and norm of the EP flux vectors, is correctly simulated with E39C-A, showing strong upward fluxes in the winter hemispheres and turning towards lower latitudes at higher altitudes. The new model E39C-A shows a clear difference between the summer and winter hemispheres which is less pronounced in the previous version E39C, particularly during the Northern Hemisphere winter season. A reason is that the summer easterlies in the extra-tropical lower stratosphere (below $10 \mathrm{hPa}$ ) are only insufficiently represented by E39C, allowing planetary waves to propagate higher into the summer stratosphere. The patterns of EP divergence (colour coded in Fig. 1) are associated with wave dissipation and represent an ideal diagnostic tool to quantify the effects of waves on the mean state. Furthermore, the mean

\footnotetext{
${ }^{1}$ Integrated mass between two latitude circles $\varphi$ and $\varphi+d \varphi$ and in the pressure interval $d p$.
} 

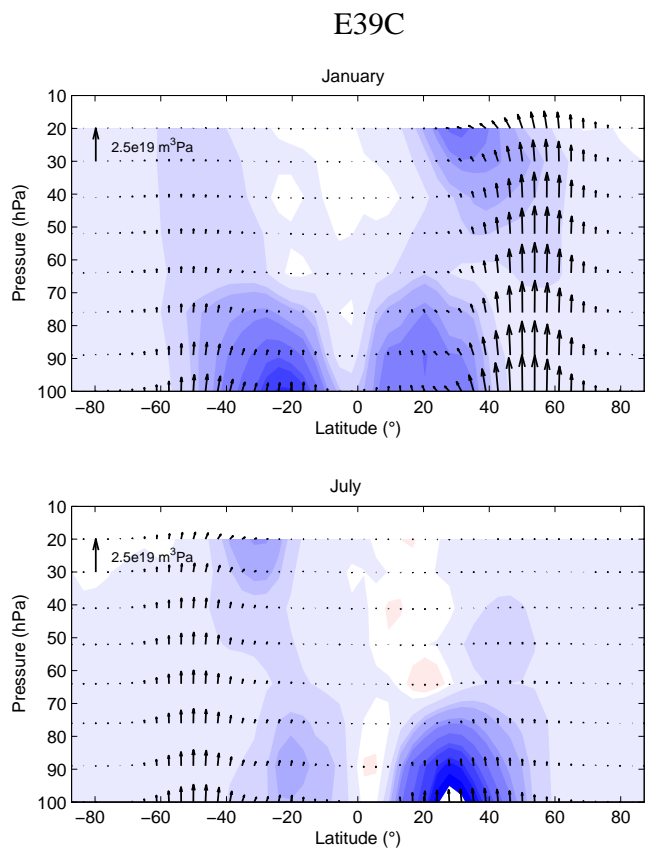
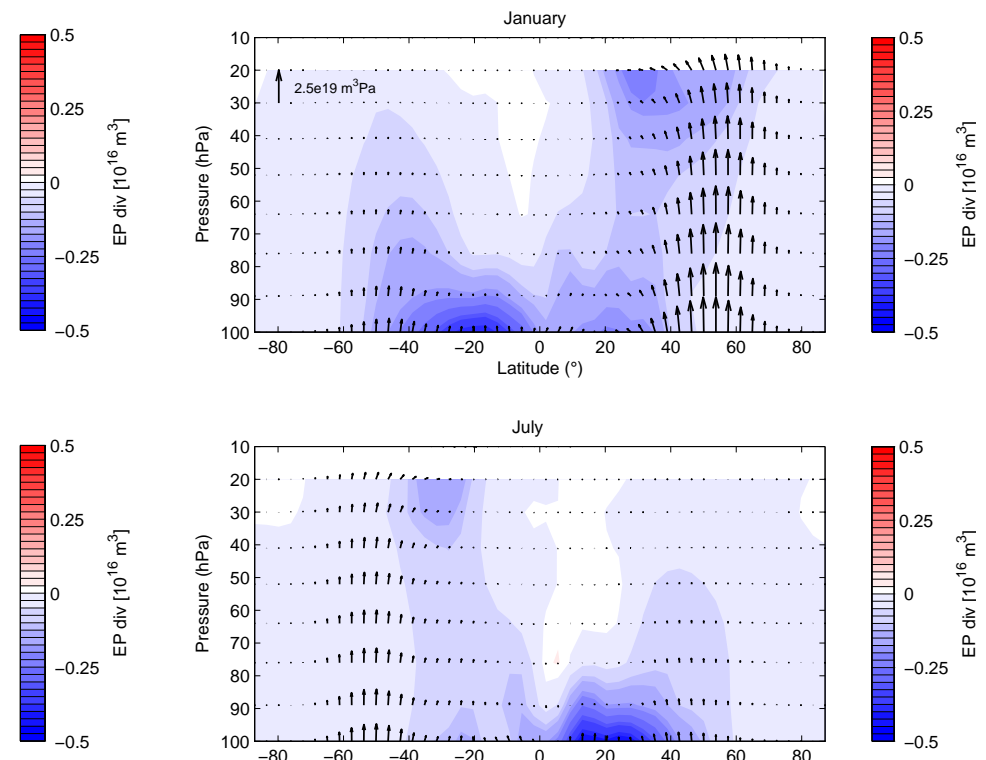

Fig. 1. January and July climatologies of EP fluxes (black arrows) and their divergences (coloured) over 40 years (1960-1999) calculated from E39C (left) and E39C-A (right). Divergences are given in units of $\mathrm{m}^{3}$ and fluxes in $\mathrm{m}^{3}$ (horizontal component) and $\mathrm{m}^{3} \mathrm{~Pa}$ (vertical component) due to weighting by mass (see text). The scale of the vertical flux is indicated in the upper left corner of the upper panel, a horizontal arrow of same length represents a flux of $0.436 \times 10^{16} \mathrm{~m}^{3}$.

meridional circulation in the stratosphere is largely driven by wave dissipation as quantified by EP divergence (via downward control as explained by Haynes et al., 1991). The EP divergence fields of E39C-A calculated for solstice conditions are in reasonable agreement with respective analyses from long-term reanalyses (see e.g. Hitchman and Huesmann, 2007), for example indicating a more pronounced region of EP convergence, i.e. imposing stronger westward forces, in the Northern Hemisphere winter stratosphere than in southern winter. As mentioned above, the more realistic simulation of stratospheric winds by E39C-A compared to E39C leads to changes in wave propagation. This causes EP divergences to be generally smaller in E39C-A and therefore a decreased forcing on the mean meridional circulation. The resulting change in tropical upwelling is further discussed in Sect. 3.2.1.

The second diagnostic we use to quantify the wave forcing of the stratosphere is given in terms of the meridional heat flux $\left(\overline{v^{\prime} T^{\prime}}\right)$ at $100 \mathrm{hPa}$ which is proportional to the vertical component of the EP flux entering the lower stratosphere. The correlation of heat fluxes at $100 \mathrm{hPa}$ (averaged over $40^{\circ} \mathrm{N}$ to $80^{\circ} \mathrm{N}$ for January/February and $40^{\circ} \mathrm{S}$ to $80^{\circ} \mathrm{S}$ for July/August, respectively) versus temperature at $50 \mathrm{hPa}$ (averaged over $60^{\circ} \mathrm{N}$ to $90^{\circ} \mathrm{N}$ for February/March and $60^{\circ} \mathrm{S}$ to $90^{\circ} \mathrm{S}$ for August/September, respectively), which was introduced by Newman et al. (2001), is used to estimate the connection between wave activity and the temperature response

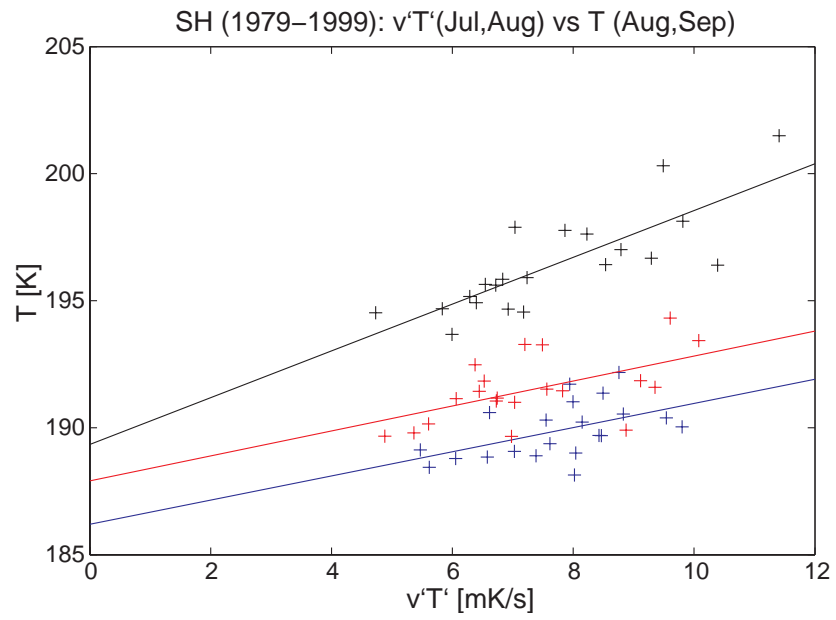

Fig. 2. Heat flux $\left(\overline{v^{\prime} T^{\prime}}\right)$ at $100 \mathrm{hPa}$ averaged over $40^{\circ} \mathrm{S}$ to $80^{\circ} \mathrm{S}$ for July and August versus temperature at $50 \mathrm{hPa}$ averaged over $60^{\circ} \mathrm{S}$ to $90^{\circ} \mathrm{S}$ for August and September. Shown are 21 years from 1979 to 1999 for E39C (blue), E39C-A (red) and NCEP/NCAR reanalyses (black) together with their linear fits (solid lines). The slope of both models differ significantly from the observations at a $95 \%$ level.

of the lower stratosphere. Figure 2 compares the model results for the Southern Hemisphere with NCEP/NCAR reanalyses. Both model versions show a statistically significant 
(on the 95\% level) flatter slope of the correlation between temperature and heat flux which indicates that the temperature response to changes in the wave forcing is underestimated. The vertical offset between model results and meteorological analyses reflects the simulated cold bias in the lower stratosphere which is clearly reduced in the new model version E39C-A. As mentioned above a large fraction of the cold bias in the previous version E39C was caused by excessive longwave cooling due to the simulated wet bias. The reasons for the problems in the simulated dynamical response to wave forcing are highly speculative. As shown in Austin et al. (2003) and Eyring et al. (2006) there seems to be no direct link between problems in the simulated temperatureheat flux relationship and horizontal model resolution. That means, that low as well as high resolution models are in principle capable of reproducing the observed temperature response to wave forcing. In our case deficiencies in the representation of the stratosphere due to the low model top and resulting deficiencies in the simulated mean zonal wind field might impact the simulated dissipation of wave energy. In the Northern Hemisphere (not shown, cp. Fig. 3 in Eyring et al., 2006, for E39C) both model versions E39C and E39CA correctly reproduce the slope of the linear fit. Since the cold bias is reduced in E39C-A, the vertical displacement is again slightly reduced.

In the following sections the implications of the Lagrangian scheme for stratospheric transport and simulated tracer distributions are discussed. It should be mentioned that the following results do not only reflect the impact of the advanced numerics of the advection algorithm, but also feedback effects of the above presented changes in model dynamics.

\subsection{Stratospheric transport}

The stratospheric transport characteristics of the new model version E39C-A including the Lagrangian advection scheme are examined by various diagnostics which have already been presented for the previous model version E39C in Eyring et al. (2006). First, the vertical ascent in the tropics as well as the tropical-extratropical mixing are evaluated by means of the atmospheric tape recorder signal (Mote et al., 1996). Information about the downward transport inside the polar vortex is obtained from the simulated methane distribution.

\subsubsection{Atmospheric tape recorder}

The atmospheric tape recorder signal is triggered by the annual temperature variations at the tropical cold point tropopause. The mean annual cycle of temperatures near the tropical tropopause $(100 \mathrm{hPa})$ is shown in Fig. 3 (left). To facilitate the comparison with ERA40 data the $100 \mathrm{hPa}$ temperatures are used instead of the cold point temperature. The previous model version E39C overestimates the ERA40 temperatures at this level by about $2-3 \mathrm{~K}$, and, consequently, the observed water vapour mixing ratios by about 3 ppmv (Fig. 3 right). Furthermore, E39C overestimates the amplitude of the water vapour annual cycle by about $1 \mathrm{ppmv}$. The upgraded model version E39C-A shows much better agreement with reanalyses and observations, both in terms of absolute values (see also Stenke et al., 2008) and in terms of the seasonal variation.

The annual variations in water vapour mixing ratios at the tropical tropopause propagate upward into the tropical stratosphere providing information about the ascent rate and the subtropical transport barrier. Figure 4 shows the timeheight section of water vapour deviations averaged between $10^{\circ} \mathrm{N}$ and $10^{\circ} \mathrm{S}$, the atmospheric tape recorder, for E39C and E39C-A. HALOE observations (Grooß and Russell III, 2005) are used for comparison. The amplitude of the water vapour deviations throughout the lowermost stratosphere is induced by the variations of the cold point temperature. The decay of the amplitude with height, however, is controlled by transport processes, primarily by horizontal mixing between tropics and extra-tropics. The attenuation of the tape recorder signal as simulated with the previous model E39C is in reasonable agreement with HALOE observations. However, compared to HALOE the propagation time of the tape recorder signal in E39C is less than half, indicating a too fast ascent in the tropics. Furthermore, the vertical diffusion of the applied semi-Lagrangian advection scheme contributes to the faster apparent transport.

From Fig. 4 it is evident that the simulated tape recorder signal in the new model version E39C-A is in much better agreement with HALOE than in E39C. E39C-A correctly reproduces the amplitude of the observed water vapour deviation in the tropical lowermost stratosphere. In the lower stratosphere also the decay of the tape recorder signal with height is in reasonable agreement with observations. At the uppermost model levels the attenuation in E39C-A is stronger than in E39C or observed. This might be related to a diagnostic artefact caused by the low coverage of the model grid by Lagrangian air parcels near the model top, leading to an artificial smoothing of the diagnostic output (see Sect. 2.2). In view of the phase propagation the upgraded model version E39C-A is in very good agreement with HALOE observations, indicating a significant improvement in the simulated tropical ascent compared to E39C. On the one hand, this result is associated with a reduced vertical diffusion of the Lagrangian scheme (Stenke et al., 2008). On the other hand, the tropical upward mass flux in E39C-A is approximately $25 \%$ lower than in E39C, which is in better agreement with observations. E39C overestimates the tropical upward mass flux at $100 \mathrm{hPa}$, with values of $19.4 \times 10^{9} \mathrm{~kg} / \mathrm{s}(\mathrm{DJF})$ and $16.4 \times 10^{9} \mathrm{~kg} / \mathrm{s}(\mathrm{JJA})$, by a factor of about 1.5 compared to observations and middle atmosphere models (Grewe, 2006). This slowdown of the tropical ascent in the new model version E39C-A is related to a decreased wave forcing on the mean meridional circulation as discussed in Sect. 3.1. 

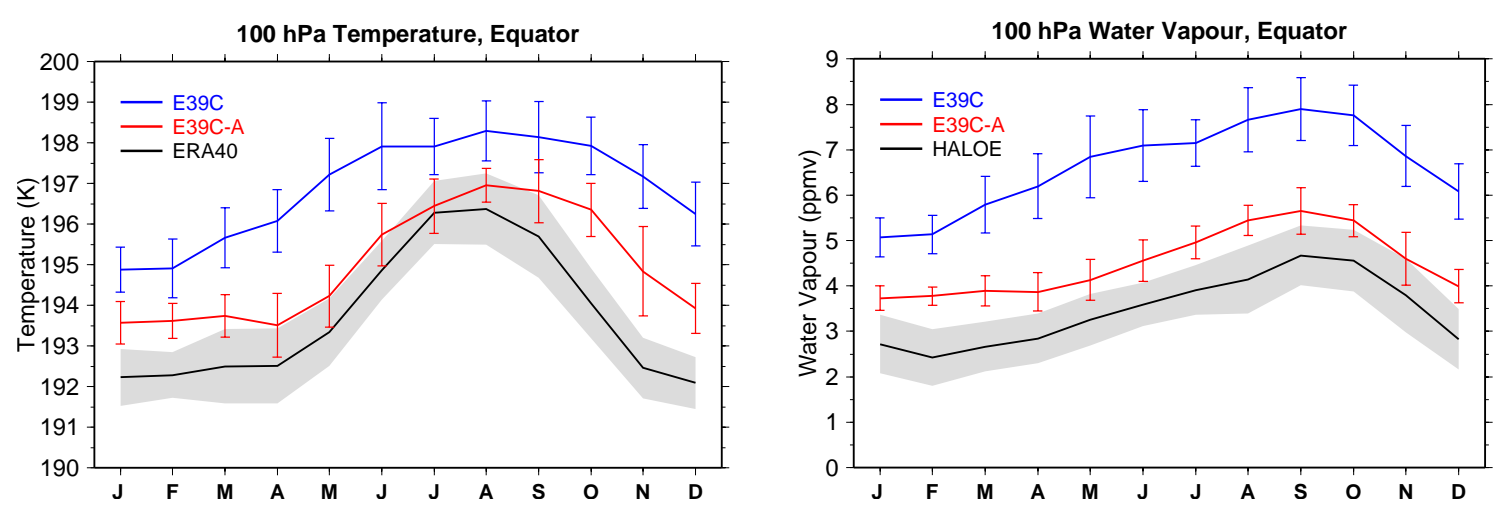

Fig. 3. Annual cycle of climatological mean temperature (left) and water vapour (right) at $100 \mathrm{hPa}$ at the equator. Model results for the $1990 \mathrm{~s}$ are compared to a temperature climatology derived from ERA-40 (1992-2001) and a HALOE water vapour climatology (1991-2002). The vertical bars and the grey shaded areas mark the standard deviation $( \pm 1 \sigma)$.
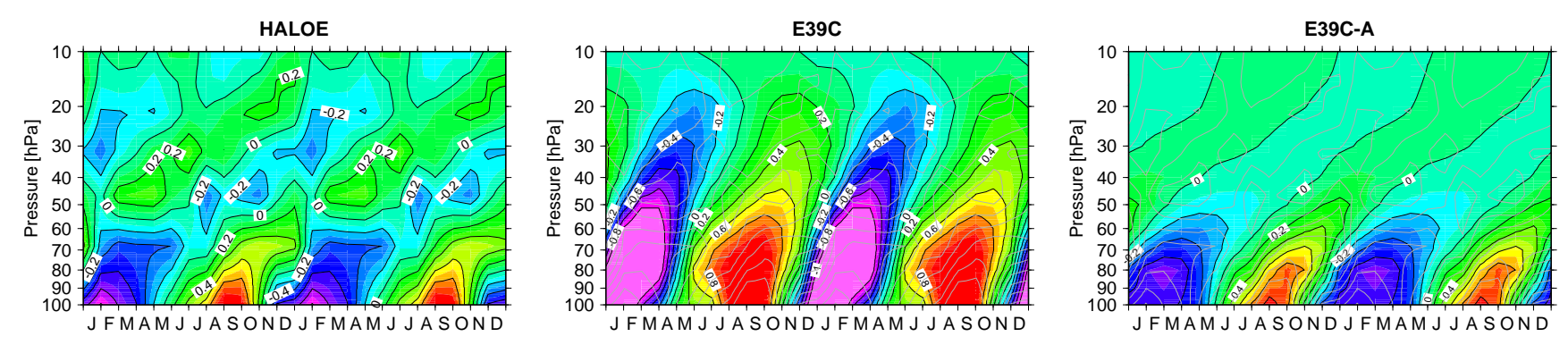

Fig. 4. Time-height sections of water vapour mixing ratio shown as the deviation [ppmv] from the mean profile, averaged between $10^{\circ} \mathrm{N}$ and $10^{\circ} \mathrm{S}$ ("atmospheric tape recorder") for HALOE observations (left), E39C (middle) and E39C-A (right). Two consecutive cycles are shown.

\subsubsection{Stratospheric methane}

The stratospheric methane concentration is mainly controlled by two processes: transport and oxidation of methane which primarily occurs in the middle and upper stratosphere. Assuming that the methane oxidation is adequately captured in the models, methane is often regarded as a suitable transport tracer, especially for downward motion inside the polar vortices.

In both model versions, E39C and E39C-A, oxidation of methane is considered, but since the model top layer is centred at $10 \mathrm{hPa}$ the main fraction of the methane oxidation occurring in the middle and upper stratosphere is not captured. Consequently, the methane content of air masses transported downwards in polar regions with the Brewer-Dobson circulation is too high. The underrepresented methane sink clearly limits the use of methane as a diagnostic for transport processes in the E39C-model family.

Figure 5 shows the zonal mean $\mathrm{CH}_{4}$ mixing ratio at $50 \mathrm{hPa}$ from E39C, E39C-A and HALOE for October in order to examine the isolated descent inside the Antarctic vortex. In extra-tropical regions the methane mixing ratios from the previous model version E39C are remarkably higher than observed, despite a reasonable performance in tropical regions.
Eyring et al. (2006) attributed this deficiency mainly to modelled transport. The new model E39C-A shows a similar performance as E39C, i.e. a good agreement with HALOE observations in the tropics and a clear overestimation of observed methane concentrations in the extra-tropics. The results for the Northern Hemisphere spring time (March) are similar and therefore not shown.

In order to unravel the effect of the unrepresented methane sink, sensitivity simulations have been performed including an upper boundary condition for methane: at $10 \mathrm{hPa}$ the observed (HALOE) horizontal methane gradient, normalised to the methane mixing ratio in the deep tropics, is prescribed. The prescribed meridional gradient is then multiplied with the actual simulated methane mixing ratio in the tropics to receive the upper boundary condition. The results of these sensitivity simulations are also included in Fig. 5 (indicated as "with UB"). Including an upper boundary condition for methane the new model version E39C-A applying the Lagrangian advection scheme is in much better agreement with HALOE observations, especially in the Northern Hemisphere. In polar regions of the Southern Hemisphere the simulated methane values are about $0.3-0.4$ ppmv (approx. $25 \%$ ) lower than in the model version without upper boundary condition, but the model results still exceed the 
observations by about 0.3 ppmv. Nevertheless, the simulated methane bias is reduced by $50 \%$. In case of the previous model version E39C the consideration of an upper boundary condition for methane leads to a reduction of the simulated methane excess in northern extra-tropics, comparable to E39C-A. In southern high latitudes, however, the improvement in E39C is only marginal. For March (not shown) the sensitivity simulations reveal similar results: in the summer (Southern) Hemisphere both models show a reduced methane bias, while in northern high latitudes only the results from E39C-A indicate a clear improvement.

The unrepresented methane sink clearly contributes to the simulated methane excess in the extra-tropical lower stratosphere. In case of the semi-Lagrangian transport scheme (E39C) the effect of the upper boundary condition is counteracted by too strong horizontal mixing across the vortex edge due to enhanced numerical diffusion, while the Lagrangian scheme ATTILA maintains steeper gradients and therefore better represents the polar barrier. The remaining methane excess in the Lagrangian model version E39C-A suggests that the simulated descent inside the polar vortices is not strong enough which may be regarded as an effect of the low upper boundary (see also Hein et al., 2001). Additionally, the study of Struthers et al. (2008) indicated that the transport barrier at the polar vortex is too weak in both model versions, E39C and E39C-A.

\subsubsection{Mean age of air}

The mean age of air is defined as the mean transit time of air masses from the tropical tropopause to a certain point in the stratosphere, and provides useful insights into stratospheric transport processes (e.g. Hall et al., 1999; Reithmeier et al., 2008). In the present study the calculation of the age of air is not based on inert tracers like $\mathrm{SF}_{6}$ or $\mathrm{CO}_{2}$, but on Lagrangian trajectories. After a sufficiently long spin-up time (approx. 10 years) the age spectrum at a certain point in the stratosphere is simply calculated by sampling the trajectories around that point with respect to their transit time since entering the stratosphere. In order to calculate the mean age of air, each air parcel was furnished with a clock, which was held at zero in the troposphere and thus measured the time elapsed since an air parcel (in the stratosphere) crossed the tropopause. In case of the previous model version E39C the Lagrangian advection scheme ATTILA has not been used to transport tracers, but the calculated trajectories have only been used to determine the age of stratospheric air. A more detailed description of the applied method is given in Reithmeier et al. (2008).

Figure 6 shows the age spectrum from both models E39C and E39C-A at the equator and at $60^{\circ} \mathrm{N}$ at $25 \mathrm{hPa}$. The mean age is shown by the vertical dashed lines, the spectral width by the horizontal dashed lines. In general, stratospheric air in E39C-A is older than in E39C which indicates a slowdown of the mean meridional circulation. This finding is consistent

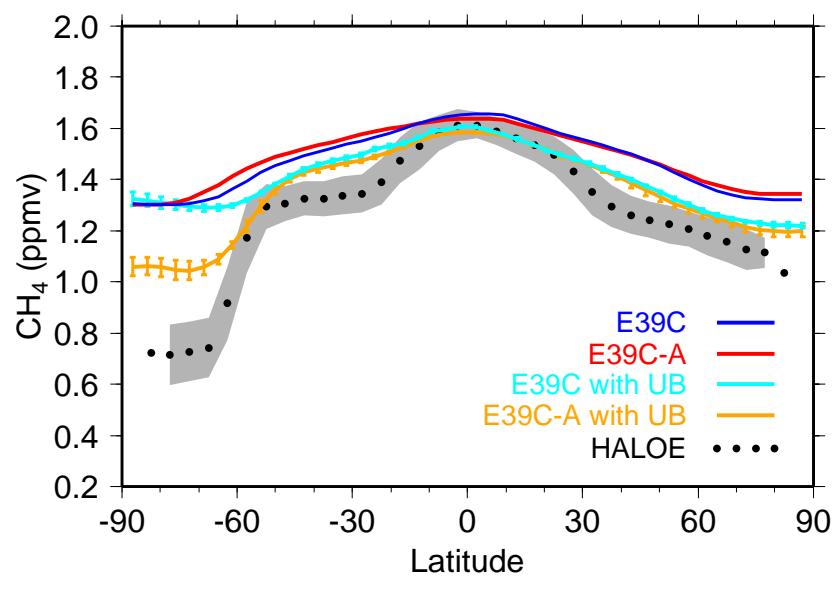

Fig. 5. Climatological zonal mean (1990 to 1999) $\mathrm{CH}_{4}$ mixing ratios [ppmv] at $50 \mathrm{hPa}$ in October for E39C (blue) and E39C-A (red). Light blue (E39C) and orange (E39C-A) show the sensitivity of the simulation to using an upper boundary condition with a meridionally varying $\mathrm{CH}_{4}$ gradient. The grey area marks the HALOE standard deviation $( \pm 1 \sigma)$.

with the above mentioned changes in the atmospheric tape recorder. In mid and high latitudes the mean age of air in the new model version E39C-A is approximately 1 year higher than in E39C, in the tropics $0.5-0.75$ years. With mean age values of about 1.5 years in tropical regions and 4.5 years at high latitudes at $50 \mathrm{hPa}$ E39C-A agrees well with different observations (Hall et al., 1999; Eyring et al., 2006). Furthermore, the spectral width for E39C-A is larger than for E39C. This increase indicates a higher interannual variability which also states a clear improvement compared to the previous model E39C (Sect. 3.1).

\subsection{Tracer distributions}

In this section we examine the implications of the Lagrangian transport for simulated tracer distributions with a focus on ozone and ozone-relevant trace species. First, the distribution of inorganic chlorine $\left(\mathrm{Cl}_{\mathrm{y}}\right)$ in the Southern Hemisphere polar spring is analysed, since stratospheric chlorine acts as a key driver for ozone depletion.

\subsubsection{Inorganic Chlorine $\left(\mathrm{Cl}_{\mathbf{y}}\right)$}

Figure 7 shows the climatological mean $\mathrm{Cl}_{\mathrm{y}}$ profile at $80^{\circ} \mathrm{S}$ for November. The vertical $\mathrm{Cl}_{\mathrm{y}}$ profile provides information to what extent air masses from the upper stratosphere (high $\mathrm{Cl}_{\mathrm{y}}$ values) descend inside the polar vortex without horizontal mixing across the vortex edge. In the previous model version E39C including semi-Lagrangian transport polar $\mathrm{Cl}_{\mathrm{y}}$ (Fig. 7) and $\mathrm{HCl}$ (see Fig. S4 in the supplement) profiles are generally shifted upwards which leads to an underestimation of the $\mathrm{Cl}_{\mathrm{y}}$ and $\mathrm{HCl}$ concentrations at lower stratospheric 

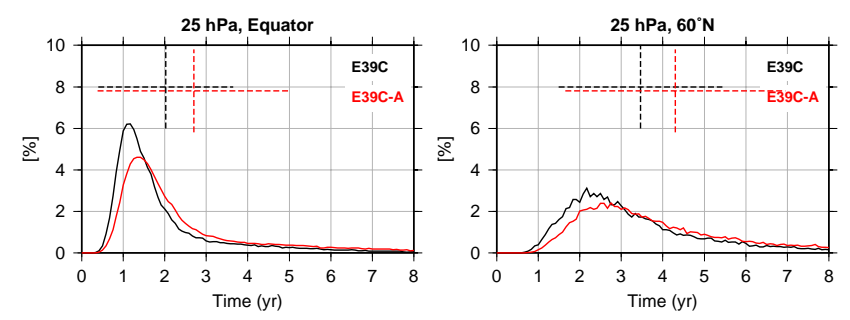

Fig. 6. The annual mean age spectrum for E39C (black) and E39CA (red) at the equator and $60^{\circ} \mathrm{N}$ at $25 \mathrm{hPa}$. The mean age of air is indicated by the vertical dashed line, and the spectral width by the horizontal dashed line.

levels. As a consequence E39C also simulates an unrealistic ozone hole profile in the Antarctic stratosphere (Hein et al., 2001; Eyring et al., 2006, see Sect. 3.3.2).

Consistent with the findings of the previous section, the Lagrangian transport in E39C-A leads to a significant improvement with regard to the simulated $\mathrm{Cl}_{\mathrm{y}}$ profile. Compared to $\mathrm{E} 39 \mathrm{C}$ high stratospheric $\mathrm{Cl}_{\mathrm{y}}$ concentrations extend further downward in E39C-A which is in good agreement with the simulated profiles of the majority of CCMs (grey lines in Fig. 7). This result holds also for the simulated $\mathrm{HCl}$ distribution (see Fig. S4 in the supplement): $\mathrm{HCl}$ at lower stratospheric levels $(50 \mathrm{hPa})$ is significantly higher than in the previous version E39C and agrees well with HALOE observations.

For reliable simulations of the temporal evolution of ozone and ozone recovery, it is important to reproduce not only the mean $\mathrm{Cl}_{\mathrm{y}}$ distribution, but also the temporal evolution of the stratospheric $\mathrm{Cl}_{\mathrm{y}}$ concentrations in response to the increasing CFC loading. Figure 8 shows the time series of $\mathrm{Cl}_{\mathrm{y}}$ in the Antarctic lower stratosphere in October (left) and the annual mean for the northern mid latitudes (right). Though the reference model version E39C simulates a $\mathrm{Cl}_{\mathrm{y}}$ increase during the 1980s and 1990s, the simulated $\mathrm{Cl}_{\mathrm{y}}$ values are generally too low and the rate of increase is too weak. In contrast the upgraded model version E39C-A shows much higher peak $\mathrm{Cl}_{\mathrm{y}}$ values during the second half of the 1990s. After 2000 the model simulates a beginning decrease of the stratospheric $\mathrm{Cl}_{\mathrm{y}}$ which is consistent with the prescribed $\mathrm{Cl}_{\mathrm{y}}$ upper boundary condition. In the northern mid latitudes E39C-A agrees very well with observations. In the Antarctic stratosphere the simulated $\mathrm{Cl}_{\mathrm{y}}$ values in E39C-A for the year 1992 are also within the uncertainty range of the observations. In 2004 E39C-A simulates a mean $\mathrm{Cl}_{\mathrm{y}}$ value of around $2.6 \mathrm{ppbv}$, while Aura MLS $\mathrm{HCl}$ measurements indicate a value of $3.3 \mathrm{ppbv}$. However, as already discussed in Eyring et al. (2006) there are large uncertainties of 10 to $15 \%$ in these values because of the limited data available and possible biases in $\mathrm{HCl}$ measurements (Lary and Aulov, 2008).

In both model versions the photolysis of organic chlorine species in the upper stratosphere is considered by an up-

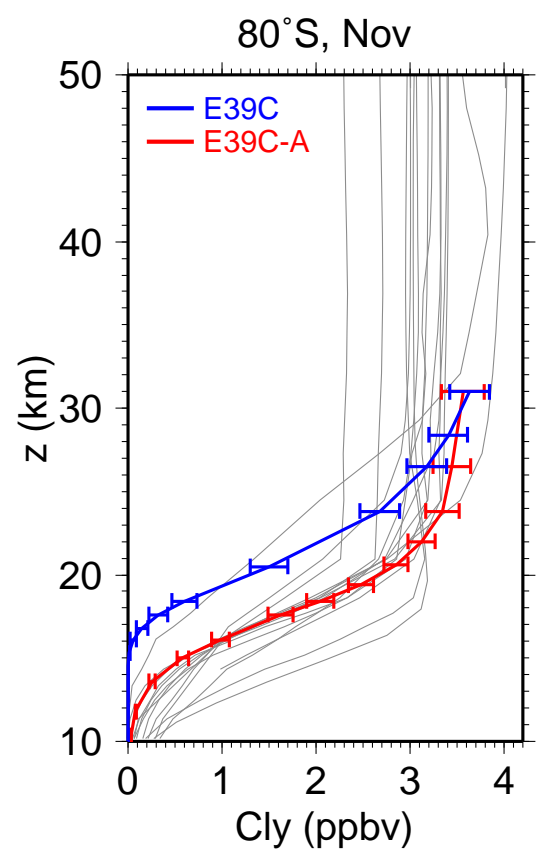

Fig. 7. Climatological mean (1990 to 1999) vertical profiles at $80^{\circ} \mathrm{S}$ in November for $\mathrm{Cl}_{\mathrm{y}}$ [ppbv] for E39C (blue) and E39C-A (red). The horizontal bars indicate the standard deviation $( \pm 1 \sigma)$. The grey lines show the results of all participating models from the intercomparison of Eyring et al. (2006, their Fig. 12a).
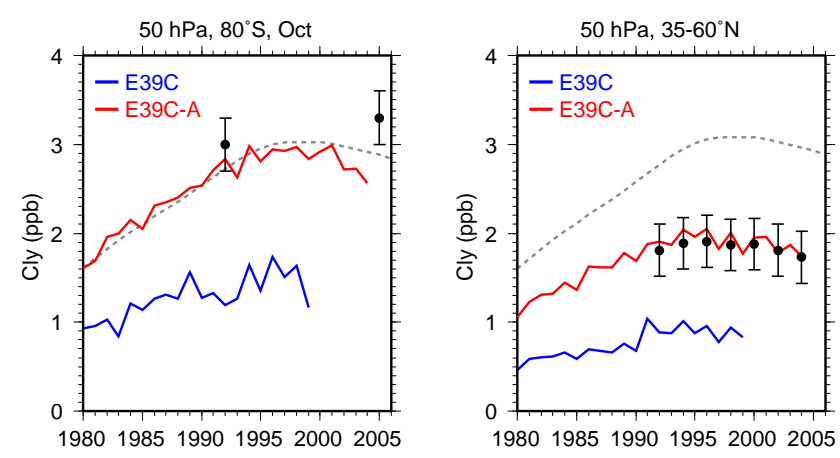

Fig. 8. Times series of (left) October mean $\mathrm{Cl}_{\mathrm{y}}$ at $80^{\circ} \mathrm{S}, 50 \mathrm{hPa}$, and (right) annual mean $\mathrm{Cl}_{\mathrm{y}}$ at $35-60^{\circ} \mathrm{N}, 50 \mathrm{hPa}$. Estimates of $\mathrm{Cl}_{\mathrm{y}}$ from various measurements are shown as black signs. The observations are taken from Waugh and Eyring (2008, their Fig. 1) The global mean $\mathrm{Cl}_{\mathrm{y}}$ mixing ratio prescribed at the model top is shown as grey line.

per boundary condition for $\mathrm{Cl}_{\mathrm{y}}$ (see Sect. 2.2). However, in $\mathrm{E} 39 \mathrm{C}$ the information about the $\mathrm{Cl}_{\mathrm{y}}$ content provided at the model top does not penetrate into the lower stratosphere. This suggests that the strong numerical diffusion of the semiLagrangian transport scheme in E39C leads to an artificial "counter-gradient-transport" in the case of low vertical resolution and large tracer gradients (Rasch and Lawrence, 1998; 
Grewe et al., 2002), resulting in an upward shift of the vertical tracer profiles. Furthermore, the considerable numerical diffusion of the semi-Lagrangian scheme also leads to a flattening of meridional tracer gradients (Reithmeier and Sausen, 2002; Stenke et al., 2008), e.g. at the vortex edge, which is not the case in the numerically non-diffusive Lagrangian advection scheme ATTILA.

\subsubsection{Ozone}

To show the direct and indirect impacts of the Lagrangian advection scheme ATTILA on the ozone distribution, a selection of ozone profiles from E39C, E39C-A and radiosonde observations are compared in Fig. 9. The observations are taken from the Binary DataBase of Profiles (BDBP), a new database of high vertical resolution measurements (Hassler et al., 2008). One main improvement of using ATTILA on the ozone profiles is a better representation of the ozonopause, i.e. the transition of low ozone concentrations in the troposphere to higher concentrations representative for the stratosphere. While in the previous model E39C this transition occurs at too high altitudes, E39C-A shows a much better agreement with observations. This effect is most evident at high latitudes (see Fig. 9), where the deviations of E39C from observations are largest (see Fig. 9 in Hein et al., 2001), but also at middle and low latitudes the simulation of the transition of ozone between troposphere and stratosphere is improved in the new model version E39C-A (not shown). One of the reasons for the downward shift of the ozonopause is certainly the improved representation of the tropopause in E39C-A (Sect. 3.1). Another reason is the reduced (vertical) diffusiveness of the Lagrangian advection scheme.

The maximum in ozone partial pressure in the stratosphere, which is already generally overestimated in the previous model E39C (cp. Fig. 9 in Hein et al., 2001), is still too high in the new model E39C-A. However, the deviation in E39C-A is slightly reduced for northern high latitudes and for mid-latitudes. Figure 9 (left) shows an example for Resolute in spring. In southern high latitudes the situation is different in that E39C-A shows even higher values of ozone than $\mathrm{E} 39 \mathrm{C}$ at all altitudes in winter (Fig. 9 right) and spring (Fig. 10 left). Note that in the previous model version E39C, the southern high latitudes are the only region where ozone is not overestimated. This may be attributed to the strong cold bias and the too weak descent inside the polar vortex. Since the cold bias is significantly reduced (Sect. 3.1) in E39C-A, ozone levels in southern polar regions are higher, being consistent with the general overestimation of total ozone in the model (see Fig. S5 in the supplement). The downward shift of the tropopause further contributes to the enhanced overestimation of total column ozone in E39C-A.

As discussed in the last section, the profiles of $\mathrm{Cl}_{\mathrm{y}}$ and $\mathrm{HCl}$ in the previous model version E39C are shifted upward. This causes the depletion of polar ozone to occur at too high levels in E39C. This is evident in Fig. 10 (left) where a typical
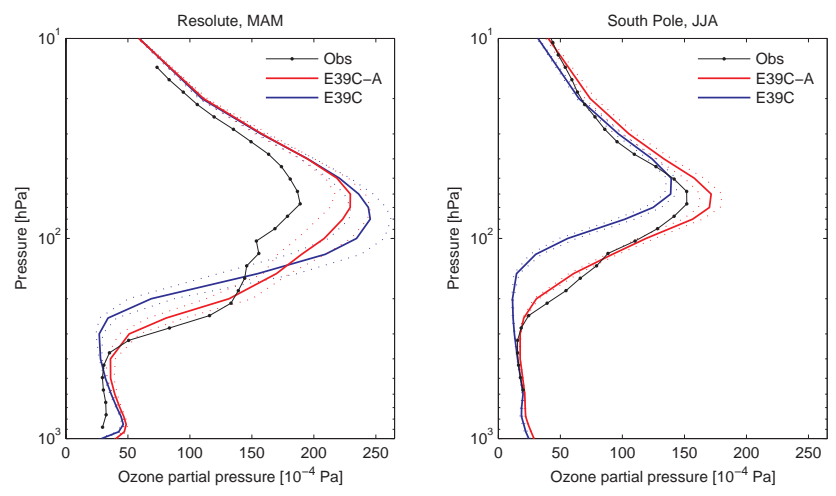

Fig. 9. Ozone partial pressure profiles for Resolute $\left(74^{\circ} \mathrm{N}, 95^{\circ} \mathrm{W}\right)$ in spring (March-May, left panel) and for the South Pole in winter (June-August, right panel). Shown are means over 1983-1989 from E39C-A (red solid lines) and E39C (blue solid lines). Dotted lines indicate the standard deviation $( \pm 1 \sigma)$. Together with modelled ozone profiles, radiosonde observations are shown (black solid lines; observations are 1983-1989 averages for Resolute and 19861987 averages for the South Pole).

year with a disturbed ozone profile is shown for E39C and E39C-A. The unrealistic minimum in ozone concentrations in $\mathrm{E} 39 \mathrm{C}$ at around $30 \mathrm{hPa}$ due to excessive $\mathrm{Cl}_{\mathrm{y}}$ values in this region is not longer apparent in the new model E39C-A. This is shown more clearly in the right panel of Fig. 10 by the relative anomaly of ozone concentrations for the perturbed conditions of the 1990s. The level of maximal ozone reduction is shifted downward from about $30 \mathrm{hPa}$ to about $50 \mathrm{hPa}$, being consistent with the downward shift of the $\mathrm{Cl}_{\mathrm{y}}$ profile (see Fig. 7). In addition, the region of ozone depletion spans over a wider range of height levels in E39C-A.

Not only the spatial but also the temporal evolution of ozone is influenced by the use of the Lagrangian advection scheme ATTILA. Even though ozone values are generally higher in the south polar region in E39C-A (see discussion above), the strong negative trend in total column ozone in spring (September to November) is greater in magnitude in E39C-A both for absolute (see Fig. 11) and relative anomalies (the trends correspond to $-8 \%$ and $-12 \%$ per decade for E39C and E39C-A, respectively). This increase in the negative trend is consistent with changes in the $\mathrm{Cl}_{\mathrm{y}}$ temporal evolution (Fig. 8). Since the previous model version E39C is underestimating the loss in total column ozone (cp. Fig. 15b in Eyring et al., 2006) the changes brought upon by ATTILA are a clear improvement towards a more realistic simulation of the evolution of atmospheric ozone.

\section{Conclusions}

In this paper we have presented the ECHAM4.L39(DLR)/ CHEM/ATTILA model (referred to as E39C-A), an improved version of the coupled chemistry-climate model 


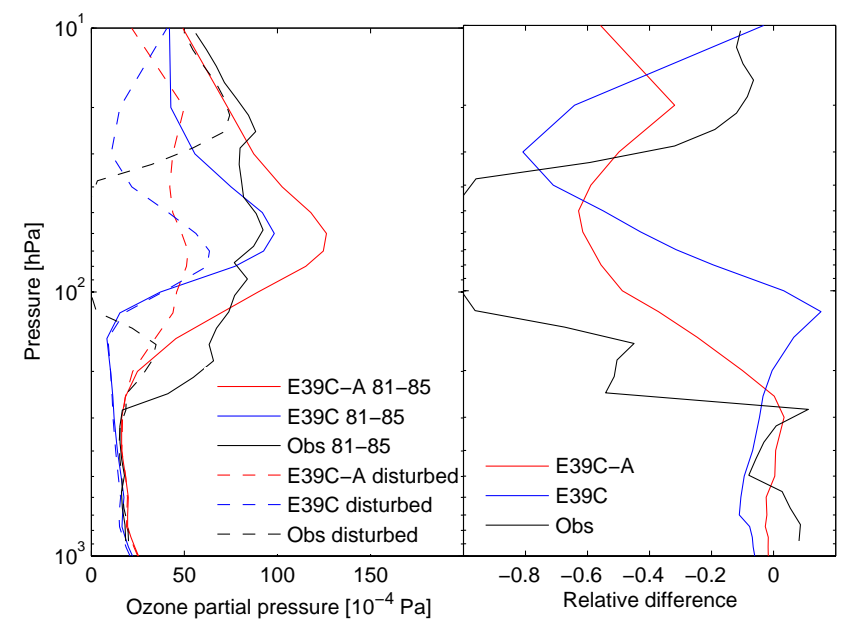

Fig. 10. Left: October mean profiles of ozone partial pressure for the South Pole for the early 1980s (solid lines; red: E39C-A, blue: E39C, black: observations) and for one year in the 1990s representative for a disturbed ozone distribution (dashed lines; red: E39CA, blue: E39C, black: observations). Right: relative difference in ozone partial pressure of the disturbed 1990s profile to the mean 1980s profile from the left panel ((disturbed - mean)/mean).

(CCM) ECHAM4.L39(DLR)/CHEM (referred to as E39C) using the purely Lagrangian scheme ATTILA for tracer transport instead of the operational semi-Lagrangian scheme by Williamson and Rasch (1994). Stratospheric model dynamics and simulated distributions of several trace species have been evaluated against observations and former model results in order to assess the implications of the Lagrangian advection scheme for the results of chemistry-climate simulations.

So far Lagrangian methods have been used for passive tracer transport (e.g. Reithmeier and Sausen, 2002) or in chemistry transport models (CTMs) (e.g. McKenna et al., 2002a,b). Recently, Stenke et al. (2008) successfully applied the Lagrangian scheme ATTILA for the transport of active trace species, i.e. water vapour and cloud water, in the general circulation model ECHAM4.L39(DLR). While in our previous paper prescribed greenhouse gas concentrations including ozone have been applied, thus neglecting the interaction of chemistry and climate, the present model study uses an interactively coupled chemistry-climate model, thus including feedback effects of the radiatively active gases ozone, nitrous oxide, methane and chlorofluorocarbons. Comparing the results of our previous study with the present model results reveals a very similar dynamical behaviour of both model versions, i.e. with and without interactively coupled chemistry, in response to the change of the advection scheme. Therefore, we believe that the changes in the water vapour distribution caused by the Lagrangian advection scheme are the key driver for improving model dy-

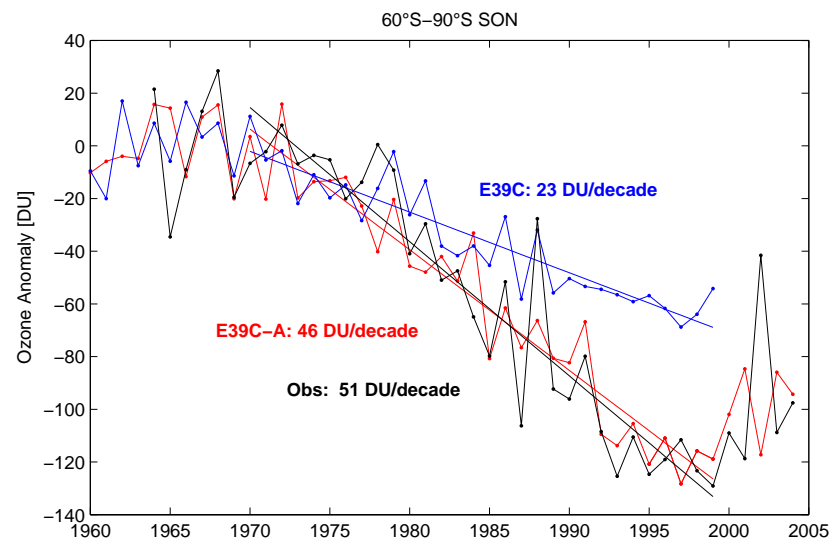

Fig. 11. Time series of total column ozone anomalies averaged over $60^{\circ} \mathrm{S}$ to $90^{\circ} \mathrm{S}$ and over September to November for E39C-A (red), E39C (blue) and observations (black, Fioletov et al., 2002). The anomalies are calculated with respect to the 1960-1969 mean (observations: 1964-1969 mean). Linear trends for the period 1970 to 1999 are added as solid lines together with their magnitude.

namics, and that the additional coupling effects on model dynamics are of minor importance.

The Lagrangian method has the advantage that it is strictly mass conserving and numerically non-diffusive. In general, the Lagrangian scheme ATTILA is able to maintain steeper and more realistic tracer gradients than the operational semiLagrangian scheme by Williamson and Rasch (1994). As shown in Stenke et al. (2008) the use of the Lagrangian scheme ATTILA leads to a reduced horizontal diffusion of water vapour from the tropical upper troposphere into the extratropical lowermost stratosphere and a remarkably reduced water vapour content in the extra-tropical lowermost stratosphere, leading to much better agreement with observations. Due to changes in the radiative heating rates, modelled temperatures also benefit from improved water vapour distribution, i.e. the simulated cold bias is reduced to one third of its original value. In response to the reduced wet and cold bias in the extra-tropical lowermost stratosphere, model dynamics show several improvements: the mean zonal wind fields are more realistically reproduced, especially the observed wind reversal in the stratosphere below $10 \mathrm{hPa}$ is now adequately simulated. Resulting changes in wave propagation and dissipation lead to a weakening of the simulated mean meridional circulation and therefore a more realistic representation of tropical upwelling. In turn, the mentioned upgrades in model dynamics are reflected in simulated tracer distributions, e.g. in the atmospheric tape recorder signal or the representation of the ozonopause. Thus, several model deficiencies in the previous model version E39C originate from a simulated moisture bias caused by the exceptional high numerical diffusion of the operational semi-Lagrangian advection scheme. 
Furthermore, Lagrangian transport and its implications for simulated tracer distributions and model dynamics have an impact on modelled chemistry. For example, the simulated distribution of inorganic chlorine $\left(\mathrm{Cl}_{\mathrm{y}}\right)$ is crucial for the simulation of stratospheric ozone depletion. Applying the Lagrangian scheme ATTILA leads to a downward shift of the polar $\mathrm{Cl}_{\mathrm{y}}$ profile in the new model version E39C-A, and therefore higher and more realistic $\mathrm{Cl}_{\mathrm{y}}$ values in the lower stratosphere. Consequently the level of maximum ozone depletion is shifted downward from $30 \mathrm{hPa}$ to $50 \mathrm{hPa}$. Furthermore, the simulated $\mathrm{Cl}_{\mathrm{y}}$ trend in the lower stratosphere, which is underestimated in E39C, is realistically reproduced in E39C-A. In response to the improved $\mathrm{Cl}_{\mathrm{y}}$ trend E39C-A shows a more realistic representation of the temporal evolution of atmospheric ozone. Hence, numerical limitations of the applied advection scheme not only affect mean spatial tracer distributions, but also the simulation of their long-term development.

Assuming that all relevant source and sink processes are adequately captured in the models, long-lived tracers like methane or nitrous oxide are commonly used to evaluate stratospheric transport characteristics. In case of the E39C model family relevant chemical source and sink processes in the upper stratosphere are not adequately captured due to the low model top centred at $10 \mathrm{hPa}$. Because of this standard tracer diagnostics may lead to misinterpretations concerning the simulated transport. Additional model simulations including an upper boundary condition for methane provide further insights into the stratospheric transport characteristics of the model. Stratospheric transport problems are not the only cause for the simulated methane excess in the extratropical lower stratosphere as assumed in previous studies (e.g. Eyring et al., 2006). A large fraction of the methane bias is related to the unrepresented stratospheric methane sink. This example and other recent studies (e.g. Müller et al., 2008) call for caution in using simple diagnostics for model evaluation without further reflection.

Model deficiencies might have different causes which certainly differ among the models. In previous studies the position of the upper boundary has been widely discussed as a potential reason for model biases in E39C (e.g. Hein et al., 2001; Austin et al., 2003; Eyring et al., 2006). The study of Stenke et al. (2008) and the present work have shown that many deficiencies in E39C are not caused by the low model top, but primarily by the exceptional high numerical diffusion of the applied semi-Lagrangian advection scheme and resultant model biases in the distributions of radiatively active trace species which feed back to model dynamics. However, Lagrangian transport can not be regarded as an universal remedy for all kind of model deficiencies. For example, the upgraded model version E39C-A still shows a low temperature bias in the polar stratosphere above $50 \mathrm{hPa}$ in winter, the so-called "cold pole" problem. Nevertheless, replacing the operational semi-Lagrangian scheme in E39C with the Lagrangian scheme ATTILA was an important step towards improved model projections. A further example for the impact of the advection scheme on the model performance is the study of Schraner et al. (2008) who showed that a change of the mass fixer significantly improved the chemical tracer distributions in the SOCOL CCM.

The detailed knowledge of the capabilities and limitations of a model system provides guidance for the interpretation of model results and which applications the model is suited for. Due to the enhanced vertical resolution in the tropopause region the model system E39C-A is predestinated for studies concerning dynamical and chemical processes in the upper troposphere/lowermost stratosphere. The calculation of Lagrangian trajectories provide a unique tool for detailed transport studies. Due to the low model top centred at $10 \mathrm{hPa}$ the model needs upper boundary conditions for certain species to account for processes in the upper stratosphere. Applying realistic boundary conditions the upgraded model version E39C-A is now able to capture the past changes in ozone providing confidence in future model predictions.

Acknowledgements. We especially thank R. Sausen for supporting the Lagrangian modelling activities in our group and for many constructive discussions. We are also grateful to $\mathrm{M}$. Ponater for his helpful comments on the manuscript. Special thanks go to B. Hassler for providing the ozonesonde profiles shown in Fig. 9, J.-U. Grooß for providing the HALOE water vapour climatology and P. Newman for providing the NCEP/NCAR heat flux data. ECMWF ERA-40 data used in this study have been obtained from the ECMWF data server. This study was supported by the European Commission through the projects SCOUT-O3 and HISAC under the 6th Framework Programme and by the German Research Foundation (DFG) through the priority programme MetStröm. Parts of the model simulations have been performed on the NEC SX-6 high performance computer of the German Climate Computing Centre (DKRZ) Hamburg. Last, but not least, we thank four reviewers and the editor for helpful and constructive comments and suggestions.

Edited by: P. Haynes

\section{References}

Atherton, C. A., Grotch, S., Parrish, D. D., Penner, J. E., and Walton, J. J.: The role of anthropogenic emissions of $\mathrm{NO}_{\mathrm{x}}$ on tropospheric ozone over the North Atlantic Ocean: A three dimensional, global model study, Atmos. Environ., 30, 1739-1749, 1996.

Austin, J., Shindell, D., Beagley, S. R., Brühl, C., Dameris, M., Manzini, E., Nagashima, T., Newman, P., Pawson, S., Pitari, G., Rozanov, E., Schnadt, C., and Shepherd, T. G.: Uncertainties and assessments of chemistry-climate models of the stratosphere, Atmos. Chem. Phys., 3, 1-27, 2003,

http://www.atmos-chem-phys.net/3/1/2003/.

Brühl, C. and Crutzen, P. J.: MPIC two-dimensional model, in: The atmospheric effects of stratospheric aircraft: Report of the 1992 models and measurement workshop, edited by: Prather, M. and Remsberg, E., NASA Reference Publ. 1292, Washington, DC, 703-706, 1993. 
Collins, W. J., Stevenson, D. S., Johnson, C. E., and Derwent, R. G.: The European regional ozone distribution and its links with the global scale for the years 1992 and 2015, Atmos. Environ., 34, 255-267, 2000.

Dameris, M., Grewe, V., Ponater, M., Deckert, R., Eyring, V., Mager, F., Matthes, S., Schnadt, C., Stenke, A., Steil, B., Brühl, C., and Giorgetta, M. A.: Long-term changes and variability in a transient simulation with a chemistry-climate model employing realistic forcing, Atmos. Chem. Phys., 5, 2121-2145, 2005, http://www.atmos-chem-phys.net/5/2121/2005/.

Edmon, H. J., Hoskins, B. J., and McIntyre, M. E.: Eliassen-Palm cross sections for the troposphere, J. Atmos. Sci., 37, 2600-2616, 1980.

Eluszkiewicz, J., Helmer, R. S., Mahlman, J. D., Bruhwiler, L., and Takacs, L. L.: Sensitivity of Age-of-Air calculations to the choice of advection scheme, J. Atmos. Sci., 57, 3185-3201, 2000.

Eyring, V., Butchart, N., Waugh, D., Akiyoshi, H., Austin, J., Bekki, S., Bodeker, G., Boville, B., Brühl, C., Chipperfield, M., Cordero, E., Dameris, M., Deushi, M., Fioletov, V., Frith, S., Garcia, R., Gettelman, A., Giorgetta, M., Grewe, V., Jourdain, L., Kinnison, D., Mancini, E., Manzini, E., Marchand, M., Marsh, D., Nagashima, T., Newman, P., Nielsen, J., Pawson, S., Pitari, G., Plummer, D., Rozanov, E., Schraner, M., Shepherd, T., Shibata, K., Stolarski, R., Struthers, H., Tian, W., and Yoshiki, M.: Assessment of temperature, trace species, and ozone in chemistry-climate model simulations of the recent past, J. Geophys. Res., 111, D22308, doi:10.1029/2006JD007327, 2006.

Fioletov, V. E., Bodeker, G. E., Miller, A. J., McPeters, R. D., and Stolarski, R.: Global and zonal total ozone variations estimated from ground-based and satellite measurements: 1964-2000, J. Geophys. Res., 107, 4647, doi:10.1029/2001JD001350, 2002.

Gates, W. L., Boyle, J. S., Covey, C., Dease, C. G., Doutriaux, C. M., Drach, R. S., Fiorino, M., Glecker, P. J., Hnilo, J. J., Marlais, S. M., Phillips, T. J., Potter, G. L., Santer, B. D., Sperber, K. R., Taylor, K. E., and Williams, D. N.: An overview of the results of the Atmospheric Model Intercomparison Project (AMIP I), B. Am. Meteorol. Soc., 80, 29-55, 1999.

Giorgetta, M. A. and Bengtsson, L.: Potential role of the quasibiennial oscillation in the stratosphere-troposphere exchange as found in water vapor in general circulation model experiments, J. Geophys. Res., 104, 6003-6019, 1999.

Grewe, V.: The origin of ozone, Atmos. Chem. Phys., 6, 14951511, 2006, http://www.atmos-chem-phys.net/6/1495/2006/.

Grewe, V., Brunner, D., Dameris, M., Grenfell, J. L., Hein, R., Shindell, D., and Staehelin, J.: Origin and variability of upper tropospheric nitrogen oxides and ozone at northern mid-latitudes, Atmos. Environ., 35, 3421-3433, 2001.

Grewe, V., Dameris, M., Fichter, C., and Sausen, R.: Impact of aircraft $\mathrm{NO}_{\mathrm{X}}$ emissions. Part 1: Interactively coupled climatechemistry simulations and sensitivities to climate-chemistry feedback, lightning and model resolution, Meteorol. Z., 3, 177186, 2002.

Grooß, J.-U. and Russell III, J. M.: Technical note: A stratospheric climatology for $\mathrm{O}_{3}, \mathrm{H}_{2} \mathrm{O}, \mathrm{CH}_{4}, \mathrm{NO}_{\mathrm{x}}, \mathrm{HCl}$ and $\mathrm{HF}$ derived from HALOE measurements, Atmos. Chem. Phys., 5, 2797-2807, 2005, http://www.atmos-chem-phys.net/5/2797/2005/.

Hall, T. M., Waugh, D. W., Boering, K. A., and Plumb, R. A.: Evaluation of transport in stratospheric models, J. Geophys. Res.,
104, 18815-18839, 1999.

Hansen, J., Sato, M., Nazarenko, L., Ruedy, R., Lacis, A., Koch, D., Tegen, I., Hall, T., Shindell, D., Santer, B., Stone, P., Novakov, T., Thomason, L., Wang, R., Wang, Y., Jacob, D., Hollandsworth, S., Bishop, L., Logan, J., Thompson, A., Stolarski, R., Lean, J., Willson, R., Levitus, S., Antonov, J., Rayner, N., Parker, D., and Christy, J.: Climate forcings in Goddard Institute for Space Studies SI2000 simulations, J. Geophys. Res., 107, 4347, doi:10.1029/2001JD001 143, 2002.

Hassler, B., Bodeker, G. E., and Dameris, M.: Technical Note: A new global database of trace gases and aerosols from multiple sources of high vertical resolution measurements, Atmos. Chem. Phys., 8, 5403-5421, 2008, http://www.atmos-chem-phys.net/8/5403/2008/.

Haynes, P. H., Marks, C. J., McIntyre, M. E., Shepherd, T. G., and Shine, K. P.: On the downward control of extratropical diabatic circulations by eddy-induced mean zonal forces, J. Atmos. Sci., 48, 651-679, 1991.

Hein, R., Crutzen, P. J., and Heimann, M.: An inverse modeling approach to investigate the global atmospheric methane cycle, Global Biogeochem. Cy., 11, 43-76, 1997.

Hein, R., Dameris, M., Schnadt, C., Land, C., Grewe, V., Köhler, I., Ponater, M., Sausen, R., B. Steil, B., Landgraf, J., and Brühl, C.: Results of an interactively coupled atmospheric chemistry general circulation model: Comparison with observations, Ann. Geophys., 19, 435-457, 2001, http://www.ann-geophys.net/19/435/2001/.

Hitchman, M. H. and Huesmann, A.: A seasonal Climatology of Rossby Wave Breaking in the 320-2000-K Layer, J. Atmos. Sci., 64, 1922-1940, 2007.

IPCC: Climate Change 2001 - The scientific basis, Intergovernmental Panel on Climate Change, Cambridge University Press, New York, USA, 2001.

Jackman, C. H., Fleming, E. L., Chandra, S., Considine, D. B., and Rosenfield, J. E.: Past, present, and future modeled ozone trends with comparisons to observed trends, J. Geophys. Res., 101, 28753-28768, 1996.

Kirchner, I., Stenchikov, G. L., Graf, H.-F., Robock, A., and Antuña, J. C.: Climate Model simulation of winter warming and summer cooling following the 1991 Mount Pinatubo volcanic eruption, J. Geophys. Res., 104, 19039-19055, 1999.

Konopka, P., Steinhorst, H. M., Grooß, J. U., Günther, G., Müller, R., Elkins, J. W., Jost, H. J., Richard, E., Schmidt, U., Toon, G., and McKenna, D. S.: Mixing and ozone loss in the 1999-2000 Arctic vortex: Simulations with the three-dimensional Chemical Lagrangian Model of the Stratosphere (CLaMS), J. Geophys. Res., 109, D02315, doi:10.1029/2003JD003792, 2004.

Lamago, D., Dameris, M., Schnadt, C., Eyring, V., and Brühl, C.: Impact of large solar zenith angles on lower stratospheric dynamical and chemical processes in a coupled chemistry-climate model, Atmos. Chem. Phys., 3, 1981-1990, 2003, http://www.atmos-chem-phys.net/3/1981/2003/.

Land, C., Feichter, J., and Sausen, R.: Impact of vertical resolution on the transport of passive tracers in the ECHAM4 model, Tellus B, 54, 344-360, 2002.

Lary, D. J. and Aulov, O.: Space-based measurements of $\mathrm{HCl}$ : Intercomparison and historical context, J. Geophys. Res., 113, D15S04, doi:10.1029/2007JD008715, 2008. 
Lean, J., Rottmann, G., Kyle, H., Woods, T., Hickey, J., and Puga, L.: Detection and parameterisation of variations in solar mid- and near-ultraviolet radiation $(22-400 \mathrm{~nm})$, J. Geophys. Res., 102, 29939-29956, 1997.

McKenna, D. S., Grooß, J.-U., Günther, G., Konopka, P., Müller, R., Carver, G., and Sasano, Y.: A new Chemical Lagrangian Model of the Stratosphere (CLAMS): 2. Formulation of chemistry scheme and initialization, J. Geophys. Res., 107, 4256, doi:10.1029/2000JD000113, 2002a.

McKenna, D. S., Konopka, P., Grooß, J.-U., Günther, G., Müller, R., Spang, R., Offermann, D., and Orsolini, Y.: A new Chemical Lagrangian Model of the Stratosphere (CLAMS): 1. Formulation of advection and mixing, J. Geophys. Res., 107, 4309, doi:10.1029/2000JD000114, 2002b.

Mote, P. W., Rosenlof, K. H., McIntyre, M. E., Carr, E. S., Gille, J. C., Holton, J. R., Kinnersley, J. S., Pumphrey, H. C., Russell III, J. M., and Waters, J. W.: An Atmospheric Tape Recorder: The Imprint of Tropical Tropopause Temperatures on Stratospheric Water Vapor, J. Geophys. Res., 101, 3989-4066, 1996.

Müller, R., Grooß, J.-U., Lemmen, C., Heinze, D., Dameris, M., and Bodeker, G.: Simple measures of ozone depletion in the polar stratosphere, Atmos. Chem. Phys., 8, 251-264, 2008, http://www.atmos-chem-phys.net/8/251/2008/.

Newman, P., Nash, E., and Rosenfield, J.: What controls the temperature of the Arctic stratosphere during the spring?, J. Geophys. Res., 106, 19999-20010, 2001.

Park, J. H., Ko, M. K. W., Jackman, C. H., Plumb, R. A., Kaye, J. A., and Sage, K. H.: Models and Measurements Intercomparison 2, Tech. Rep. NASATM-1999-209554, NASA, 1999.

Pawson, S., Kodera, K., Hamilton, K., Shepherd, T. G., Beagley, S. R., Boville, B., Farrara, J. D., Fairlie, T. D. A., Kitoh, A., Lahoz, W. A., Langematz, U., Manzini, E., Rind, D. H., Scaife, A. A., Shibata, K., Simon, P., Swinbank, R., Takacs, L., Wilson, R., Al-Saadi, J. A., Amodei, M., Chiba, M., Coy, L., de Grandpre, J., Eckman, R. S., Fiorino, M., Grose, W. L., Koide, H., Koshyk, J. N., Li, D., Lerner, J., Mahlman, J. D., McFarlane, N. A., Mechoso, C. R., Molod, A., O’Neill, A., Pierce, R. B., Randel, W. J., Rood, R. B., and Wu, F.: The GCM-reality intercomparison project of SPARC (GRIPS): scientific issues and initial results, B. Am. Meteorol. Soc., 81, 781-796, 2000.

Rasch, P. J. and Lawrence, M.: Recent development in transport methods at NCAR, Report No. 265, Max-Planck-Institut für Meteorologie, Hamburg, 1998.

Rasch, P. J. and Williamson, D. L.: Computational aspects of moisture transport in global models of the atmosphere, Q. J. Roy. Meteor. Soc., 116, 1071-1090, 1990.

Rayner, N. A., Parker, D. E., Horton, E. B., Folland, C. K., Alexander, L. V., Rowell, D. P., Kent, E. C., and Kaplan, A.: Global Analyses of sea surface temperatures, sea ice, and night marine air temperature since the late nineteenth century, J. Geophys. Res., 108, 4407, doi:10.1029/2002JD002670, 2003.

Reithmeier, C. and Sausen, R.: ATTILA: Atmospheric Tracer Transport in a Lagrangian Model, Tellus B, 54, 278-299, 2002.

Reithmeier, C., Sausen, R., and Grewe, V.: Investigating lower stratospheric model transport: Lagrangian calculations of mean age and age spectra in the GCM ECHAM4, Clim. Dynam., 30, 225-238, 2008.

Rex, M., Salawitch, R. J., Santee, M. L., Waters, J. W., Hoppel, K., and Bevilacqua, R.: On the unexplained stratospheric ozone losses during cold Arctic Januaries, Geophys. Res. Lett., 30, 1008, doi:10.1029/2002GL016008, 2003.

Robinson, W. A.: The Application of the Quasi-Geostrophic Eliassen-Palm Flux to the Analysis of Stratospheric Data, J. Atmos. Sci., 43, 1017-1024, 1986.

Roeckner, E., Arpe, K., Bengtsson, L., Christoph, M., Claussen, M., Dümenil, L., Esch, M., Giorgetta, M., Schlese, U., and Schulzweida, U.: The atmospheric general circulation model ECHAM-4: Model description and simulation of present-day climate, Report No. 218, Max-Planck-Institut für Meteorologie, Hamburg, 1996.

Sato, M., Hansen, J. E., McCormick, M. P., and Pollack, J. B.: Stratospheric aerosol optical depths, 1850-1990, J. Geophys. Res., 98, 22987-22994, 1993.

Schmidt, G. A., Ruedy, R., Hansen, J. E., Aleinov, I., N. Bell, Bauer, M., Bauer, S., Cairns, B., Canuto, V., Cheng, Y., Genio, A. D., Faluvegi, G., Friend, A. D., Hall, T. M., Hu, Y., Kelley, M., Kiang, N. Y., Koch, D., Lacis, A. A., Lerner, J., Lo, K. K., Miller, R. L., Nazarenko, L., Oinas, V., Perlwitz, J., Perlwitz, J., Rind, D., Romanou, A., Russell, G. L., Sato, M., Shindell, D. T., Stone, P. H., Sun, S., Tausnev, N., Thresher, D., and Yao, M.S.: Present-day atmospheric simulations using GISS Model E: Comparison to in situ, satellite, and reanalysis data, J. Climate, 19, 153-192, doi:10.1175/JCLI3612.1, 2006.

Schraner, M., Rozanov, E., Schnadt Poberaj, C., Kenzelmann, P., Fischer, A. M., Zubov, V., Luo, B. P., Hoyle, C. R., Egorova, T., Fueglistaler, S., Brönnimann, S., Schmutz, W., and Peter, T.: Technical Note: Chemistry-climate model SOCOL: version 2.0 with improved transport and chemistry/microphysics schemes, Atmos. Chem. Phys., 8, 5957-5974, 2008,

http://www.atmos-chem-phys.net/8/5957/2008/.

Sheel, V., Lal, S., and Brühl, C.: Validation of a 2D model using observed profiles of $\mathrm{SF}_{6}$ with main focus on the tropics, Atmos. Environ., 39, 1255-1261, 2005.

Steil, B., Dameris, M., Brühl, C., Crutzen, P. J., Grewe, V., Ponater, M., and Sausen, R.: Development of a chemistry module for GCMs: first results of a multiannual integration, Ann. Geophys., 16, 205-228, 1998, http://www.ann-geophys.net/16/205/1998/.

Stenke, A., Grewe, V., and Ponater, M.: Lagrangian transport of water vapour and cloud water in the ECHAM4 GCM and its impact on the cold bias, Clim. Dynam., 31, 491-506, doi:10.1007/s00382-007-0347-5, 2008.

Struthers, H., Bodeker, G. E., Austin, J., Bekki, S., Cionni, I., Dameris, M., Giorgetta, M. A., Grewe, V., Lefèvre, F., Lott, F., Manzini, E., Peter, T., Rozanov, E., and Schraner, M.: An evaluation of the simulation of the edge of the Antarctic vortex by chemistry-climate models, Atmos. Chem. Phys. Discuss., 8, 20155-20192, 2008,

http://www.atmos-chem-phys-discuss.net/8/20155/2008/.

Uppala, S. M., Kållberg, P. W., Simmons, A. J., Andrae, U., Da Costa Bechtold, V., Fiorino, M., Gibson, J. K., Haseler, J., Hernandez, A., Kelly, G. A., Li, X., Onogi, K., Saarinen, S., Sokka, N., Allan, R. P., Andersson, E., Arpe, K., Balmaseda, M. A., Beljaars, A. C. M., van de Berg, L., Bidlot, J., Bormann, N., Caires, S., Chevallier, F., Dethof, A., Dragosavac, M., Fisher, M., Fuentes, M., Hagemann, S., Hólm, E., Hoskins, B. J., Isaksen, L., Janssen, P. A. E. M., Jenne, R., McNally, A. P., Mahfouf, J.-F., Morcrette, J.-J., Rayner, N. A., Saunders, R. W., Simon, P., Sterl, A., Trenberth, K. E., Untch, A., Vasiljevic, D., Viterbo, 
P., and Woollen, J.: The ERA-40 re-analysis, Q. J. Roy. Meteor. Soc., 131, 2961-3012, 2005.

van het Bolscher, M., Pulles, T., Brand, R., Pereira, J., Spessa, A., Dalsøren, S., van Nojie, T., and Szopa, S.: Emission data sets and methodologies for estimating emissions, in: REanalysis of the TROpospheric chemical composition of the past 40 years, edited by: Schultz, M. and Rast, S., 1-77, 2007.

Waugh, D. W. and Eyring, V.: Quantitative performance metrics for stratospheric-resolving chemistry-climate models, Atmos. Chem. Phys., 8, 5699-5713, 2008,

http://www.atmos-chem-phys.net/8/5699/2008/.
Williamson, D. L. and Rasch, P. J.: Water vapor transport in the NCAR CCM2, Tellus A, 46, 34-51, 1994.

WMO: Scientific assessment of ozone depletion: 2002, Report No. 47, World Meteorological Organization, Genf, Schweiz, 2003. 